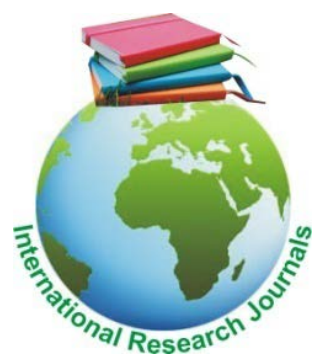

African Journal of Food Science and Technology (ISSN: 2141-5455) Vol. 9(2) pp. 37-42, July, 2018

DOI: http:/dx.doi.org/10.14303/ajfst.2018.233

Available online https://www.interesjournals.org/food-science-technology.html

Copyright (C2018 International Research Journals

Full Length Research Paper

\title{
Effect of pH and temperature on the activities of alpha-amylase in cassava starch liquefaction
}

\author{
Pele GI ${ }^{1 *}$, Bolade $\mathrm{MK}^{1}$, Enujiugha $\mathrm{VN}^{1}$, Sanni $\mathrm{DM}^{2}$, Ogunsua $\mathrm{AO}^{3}$ \\ 1Department of Food Science and Technology, Federal University of Technology, \\ Akure, Ondo State, Nigeria. \\ 2Department of Biochemistry, Federal University of Technology, Akure, \\ Ondo State, Nigeria. \\ 3Department of Food Science and Technology, Joseph Ayo Babalola University, \\ Ikeji-Arakeji, Osun State, Nigeria. \\ *Corresponding Author Email: ife_pele@ymail.com
}

\begin{abstract}
Alpha-amylase is an enzyme in the conversion of starch to maltodextrin. The study investigated the effect of $\mathrm{pH}$ and temperature on the activities of alpha-amylase in the conversion of starch to maltodextrin. The optimum condition of cassava starch hydrolysis was determined by using a pure culture of a thermostable alpha-amylase for liquefaction, and the activity of the enzyme determined at varying $\mathrm{pH}$, temperature and time. A $3 \times 3 \times 3$ completely randomized experimental design comprising $3 \mathrm{pH}$ values $(\mathrm{pH} 6.0,6.5$ and 7.0); 3 temperatures (65, 70 and $75^{\circ} \mathrm{C}$ ) and 3 time ranges $(40,50$ and $60 \mathrm{~min}$ ) were employed for liquefaction. Results showed that sample dry weight decreased with increasing value of $\mathrm{pH}$, temperature and time. The optimal reducing sugar and dextrose equivalent were $17.84 \%$ and $14.74 \mathrm{DE}$, respectively at $\mathrm{pH} 6.5,70^{\circ} \mathrm{C}$ and $60 \mathrm{~min}$. The maltodextrin obtained may serve as a substrate in glucose syrup production
\end{abstract}

Keywords: Alpha-amylase, cassava starch, hydrolysis, liquefaction, maltodextrin.

\section{INTRODUCTION}

Alpha-amylase is a biochemical catalyst that breaks the $\alpha(1,4)$ glycosidic bonds in the coversion of starch to maltodextrin which consists of D-glucose units connected in chains of variable length which are primarily composed of a mixture of chains that vary from 3 to 17 glucose units long and are classified by Dextrose Equivalent (DE) which is usually between 3 and 20 (Jane et al., 1999). The production of maltodextrin involves the abstention of products consisting of D-glucose units linked primarily by $\alpha(1,4)$ bonds having a DE lower than 20. Maltodextrins are commercially distributed as white powder or concentrated solution (Bello-Perez et al., 2002). Starch hydrolysis is traditionally done by mineral acid catalysis, but this method has been greatly deficient, as it required the use of corrosion resistant materials, giving rise to high colour and salt ash content after neutralisation, needed more energy for heating and was relatively difficult to control. However, biotechnological advances have led to obtaining enzymes that now allow the controlled production of a variety of maltodextrin. Alpha-amylase is distributed widely in plant and animal kingdoms. Alpha-amylase is an endoenzyme which hydrolyses $\alpha$ $(1,4)$ glucosidic bonds in a random fashion along the chain (Konsoula and Liakopoulou-Kyriakides, 2007). It hydrolyses amylopectin to oligosaccharides containing 2 to 6 glucose units. This action leads to a rapid decrease in viscosity but little monosaccharide formation (Pandey et al., 2000). A mixture of amylose and amylopectin will be hydrolysed into a mixture of dextrins, maltose and glucose (George, 2004). Although maize starch has been traditionally used in the manufacturing of glucose syrups and maltodextrins, attention has gradually been paid to their production from non-conventional sources of starch, such as amaranth, cassava, potato, plantain and sorghum (Aboje, 2007). Cassava (Manihot esculenta 
Crantz) is one of the most essential crops in tropical regions (Aderibigbe et al., 2012); it does not cause air pollution or any environmental hazard and does not contribute to greenhouse effect problem (Ukwuru and Egbonu, 2013). It is a cheap substrate that is easily available in tropical countries and has high tolerance to drought because it can survive even during the dry season when soil moisture is low and humidity is high. Also, it can survive low soil quality or nutrient as it thrives better in poor soils than any other major food plant (Adesanya et al., 2008). The objective of the present study therefore was to evaluate the influence of $\mathrm{pH}$ and temperature on the quality of maltodextrin produced from cassava starch using $\alpha$-amylase.

\section{MATERIALS AND METHODS}

\section{Materials}

Matured cassava (Manihot esculenta) variety (TME 419) was obtained from the International Institute of Tropical Agriculture (IITA), Ibadan, Nigeria and pure culture of thermostable alpha-amylase (Amylic Tx: isolated from Bacillus amyloliquefaciens; $\mathrm{pH}$ 6.4-6.5; temperature, $80-88^{\circ} \mathrm{C}$ ) was obtained from International Brewery, llesa, Nigeria

\section{Production of Starch}

Cassava starch was produced by using the method described by the International Institute of Tropical Agriculture (IITA, 2004). The fresh cassava tubers were manually peeled with stainless steel knife and washed with tap water followed by wet milling using a hammer mill. The mash obtained was mixed with distilled water followed by filtration through a muslin cloth. The filtrate was allowed to settle ( $3 \mathrm{~h}$ ) and the supernatant decanted. The starch was then dewatered by squeezing in the muslin cloth and dried separately in a vacuum oven at $40^{\circ} \mathrm{C}$ to constant weight for $8 \mathrm{~h}$. The dried starch was broken into small lumps and milled using a double disc attrition mill and sieved. The resultant products were packaged in an air tight polyethylene bag place in plastic containers and stored on dry shelves at room conditions.

\section{Description of Fermentor}

A prototype of a fermentor was designed and fabricated to combine with thermostatic water bath (DK-600 SANFA Electrical thermostatic water bath boiler model) for liquefaction and saccharification as shown in Figure 1. The fermentor uses variable motor Gear: GIFA Transmission Bologna Italy, Type (TIPO): (Var 10/0) Code (Condice): AC3999 Motor.

Note: (Motor) Kw: 0.75; Poles: 4; Rpm min-rpm max: 350-1750; Type: mas 20P; Code: 29602117; Mount POS: 2.5.4. Bonfiglioli Riduttori, Italy.

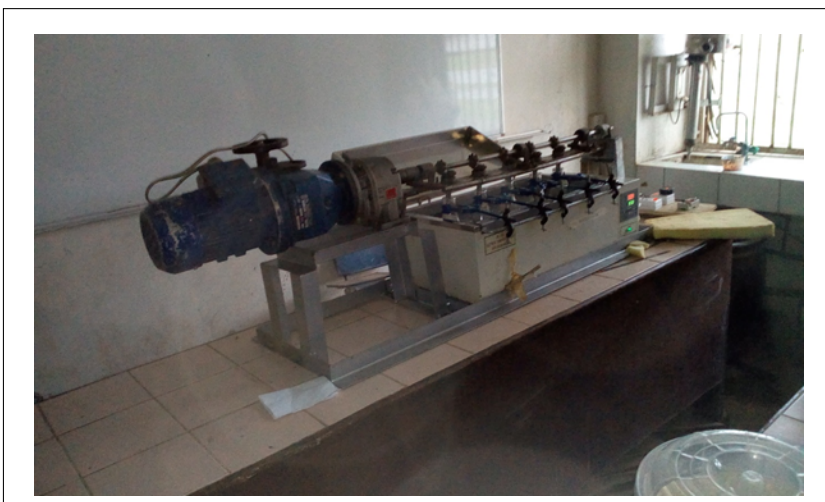

Figure 1: A locally-fabricated fermentor used for the liquefaction

Note: (Motor) Kw: 0.75; Poles: 4; Rpm min-rpm max: 350-1750; Type: mas 20P; Code: 29602117; Mount POS: 2.5.4. Bonfiglioli Riduttori, Italy.

\section{Production of Maltodextrin by Enzyme Liquefaction}

Characterization of alpha-amylase: The optimum condition of cassava starch hydrolysis was determined using pure culture of thermostable alpha-amylase for liquefaction. The activity of the enzyme was determined at varying $\mathrm{pH}$, temperature and time. A $3 \times 3 \times 3$ completely randomized experimental design comprising $3 \mathrm{pH}$ values

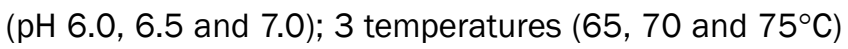
and 3 time ranges (40, 50 and $60 \mathrm{~min}$ ) were employed for liquefaction.

Determination of enzyme activity in alpha-amylase: The activity of $\alpha$-amylase on cassava starch hydrolysis was determined by the method described by Betiku and Ajala (2010). A starch suspension of $10 \%(\mathrm{w} / \mathrm{v})$ was prepared with distilled water, to make $10 \%$ slurry. Usually $10 \mathrm{~g}$ of starch was weighed into $100 \mathrm{~mL}$ distilled water to make slurry. The solution of $40 \mathrm{ppm} \mathrm{Ca}{ }^{2+}$ was added for stability of the enzyme. The $\mathrm{pH}$ was adjusted to $6.0,6.5$ and 7.0 with Citrate-phosphate buffer, respectively. Gelatinization was done by heating the mixture to $97^{\circ} \mathrm{C}$ and was held at this temperature for $10 \mathrm{~min}$. The gelatinized starch was cooled to 65,70 and $75^{\circ} \mathrm{C}$, respectively. Liquefaction was carried out by adding $2 \%(\mathrm{w} / \mathrm{v})$ of alpha-amylase for 40, 50 and 60 min at the temperatures, respectively. The fermentor was clamped with the thermostatic water-bath to maintain at $50 \mathrm{rpm}$; samples were however withdrawn at regular time intervals to follow the kinetics. The enzyme activity was stopped by heating the mixture to $97^{\circ} \mathrm{C}$ for 15 to $20 \mathrm{~min}$ and centrifuged (80-2 Centrifuge Med-Lab Scientific Company England) at $2500 \mathrm{rpm}$ for $10 \mathrm{~min}$ to obtain the supernatant for analyses. The procedures described above were done in triplicates; standard curve of glucose production was prepared to determine the optimum condition of liquefaction for cassava. 
Determination of Physicochemical Properties of Maltodextrin

Determination of reducing sugar: The reducing sugar was determined by DNS method described by Miller (1972) with the addition of Rochelle salt. The reducing sugar was determined by adding $3 \mathrm{~mL}$ of DNS solution to $1 \mathrm{~mL}$ of hydrolysed starch (supernatant) in a test tube and boiled for $10 \mathrm{~min}$. This was allowed to cool partially and 1 $\mathrm{mL}$ of Rochelle salt was added, while this was allowed to completely cool down before the intensity or absorbance of the red coloured solution was read at $540 \mathrm{~nm}$ using UVVisible Spectrophotometer (AJ-1C03). Series of standard glucose $(0-500 \mathrm{mg} / \mathrm{l})$ were run and a standard graph was plotted to calculate the reducing sugar. Percentage reducing sugar was calculated by the percentage of the ratio of the amount of reducing sugar in the glucose syrup to the amount of starch slurry for the hydrolysis.

Reducing Sugar $(\mathrm{mg} / \mathrm{mL})=\frac{\text { Conc.obt }(\mathrm{mg} / \mathrm{l}) \times \text { vol.of extractX dil.factor (if any) }}{\text { Sample wt X }}$

\section{DETERMINATION OF SAMPLE DRY WEIGHT}

Two (2) g of each of the samples was weighed out with the aid of an analytical balance into dried, cooled and weighed dish in each case. The samples in the dishes were then put into a Genlab moisture extraction oven set at $105^{\circ} \mathrm{C}$ and allowed to dry for $3 \mathrm{~h}$ after which the samples were then transferred into a dessicator with the aid of a laboratory tong and then allowed to cool for $30 \mathrm{~min}$. After cooling in the dessicator, they were weighed again and their respective weights recorded accordingly. The above processes were repeated for each sample until a constant weight was obtained in each case. The difference in weight was calculated as the sample dry weight.

\section{Determination of dextrose equivalent (DE)}

Dextrose equivalent (DE) was determined by the expression described by Betiku et al. (2013). Dextrose equivalent was calculated as the ratio of reducing sugar expressed as glucose to the sample dry weight.

$$
\mathrm{DE}=\frac{\text { Reducing sugar expressed as glucose }}{\text { Sample dry weight }}
$$

\section{Statistical Analyses}

Data obtained from the experiment were subjected to completely randomized experimental design and statistical analysis using Microsoft excel version 2010, SPSS version 20 and Mini Tab version 17.

\section{RESULTS AND DISCUSSION}

Effect of $\mathrm{pH}$ and Temperature on the Activities of Alphaamylase and Maltodextrin

Produced from Cassava: The results of the effect of
$\mathrm{pH} 6$ on the kinetics of liquefaction and maltodextrin produced from cassava starch with $\alpha$-amylase are shown in Figures 2a-c. At pH 6, liquefaction of cassava starch at $65^{\circ} \mathrm{C}$ showed that reducing sugars were 9.55, 10.09 and $10.09 \%$, respectively at 40,50 and 60 min of liquefaction time. The results showed an increase in respect of time but there is no significant difference at 50 and $60 \mathrm{~min}$. The results showed that samples dry weight were 0.143 , 0.131 and $0.127 \mathrm{~g}$, respectively at 40,50 and $60 \mathrm{~min}$ of liquefaction time; the results however showed a significant decrease in respect of time.

DE were $6.68,7.70$ and 7.94 , respectively at 40,50 , and $60 \mathrm{~min}$ of liquefaction time, results showed that there is significant increase in respect of time. The results of the effect of $\mathrm{pH} 6$ on the liquefaction of cassava starch at $70^{\circ} \mathrm{C}$ showed that reducing sugar were $11.89,13.69$ and

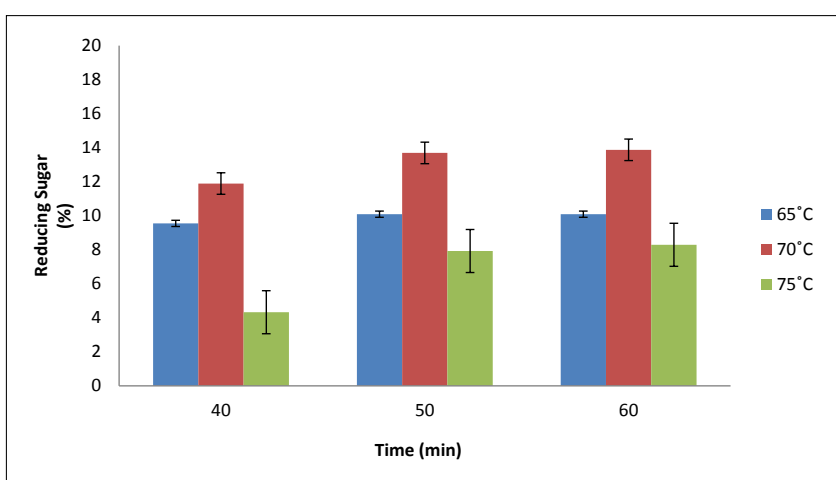

Figure 2a: Reducing sugar content during liquefaction of cassava at $\mathrm{pH} 6$

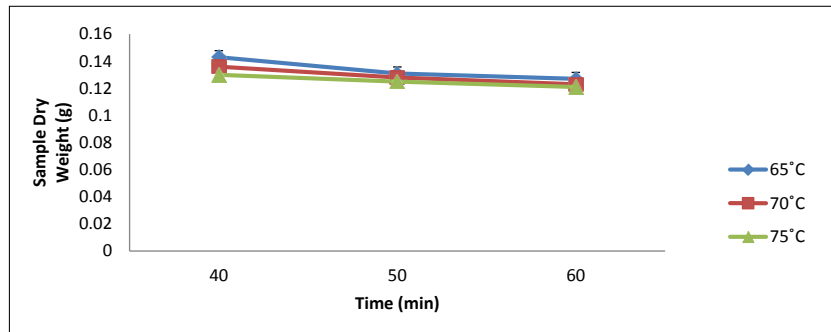

Figure 2b: Sample dry weight from liquefaction of cassava at $\mathrm{pH} 6$

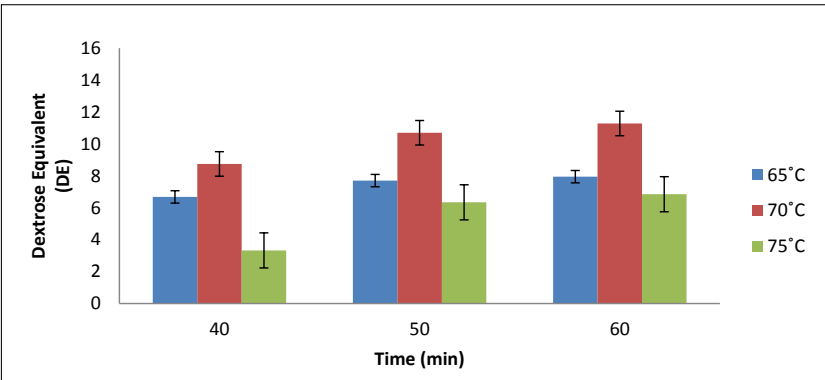

Figure 2c: Dextrose equivalent of syrup from liquefaction of cassava at $\mathrm{pH} 6$ 
$13.87 \%$, respectively at 40,50 and 60 min of liquefaction time. The results showed a significant increase in the reducing sugar in respect of time of liquefaction. The results showed that samples dry weight were 0.136 , 0.128 and $0.123 \mathrm{~g}$, respectively at 40,50 and $60 \mathrm{~min}$, results showed a significant decrease in respect of time.

Dextrose equivalent were 8.74, 10.70 and $11.27 \mathrm{DE}$, respectively at 40,50 and $60 \mathrm{~min}$ of liquefaction time, results showed a significant increase in respect of time. The results of the effect of $\mathrm{pH} 6$ on the liquefaction of cassava starch at $75^{\circ} \mathrm{C}$ showed that reducing sugar were $4.32,7.93$ and $8.28 \%$, respectively at 40,50 and 60 min of liquefaction time, results showed a significant increase in the reducing sugar in respect of time of liquefaction. The results showed that samples dry weight were 0.13 , 0.125 and $0.121 \mathrm{~g}$, respectively at 40,50 and $60 \mathrm{~min}$, results showed a significant decrease in respect of time. Dextrose equivalent were 3.32, 6.34 and $6.85 \mathrm{DE}$, respectively at 40,50 and $60 \mathrm{~min}$ of liquefaction time, results showed a significant increase in respect of time. As the liquefaction time increased, increase in reducing sugar and dextrose equivalent were observed, whereas this was in contrast with the samples dry weight, which decreased with increase in liquefaction time. The effect of temperature on the kinetics also showed that the highest level of reducing sugar and dextrose equivalent were recorded at $70^{\circ} \mathrm{C}$ with least value at $75^{\circ} \mathrm{C}$.

The results of the effect of $\mathrm{pH} 6.5$ on the kinetics of liquefaction and maltodextrin produced from cassava starch with $\alpha$-amylase are shown in Figures 3a-c. At pH 6.5 , liquefaction of cassava starch at $65^{\circ} \mathrm{C}$ showed that reducing sugars were $9.91,16.22$ and $16.76 \%$; sample dry weight were $0.138,0.129$ and $0.124 \mathrm{~g}$; and dextrose equivalent were $7.18,12.57$ and $13.51 \mathrm{DE}$, respectively of 40,50 and 60 min of liquefaction time, results showed that there is significant increase in reducing sugar and dextrose equivalent while a significant decrease was observed in sample dry weight, respectively of liquefaction time.

The results of the effect of $\mathrm{pH} 6.5$ on the liquefaction of cassava starch at $70^{\circ} \mathrm{C}$ also showed that reducing sugars

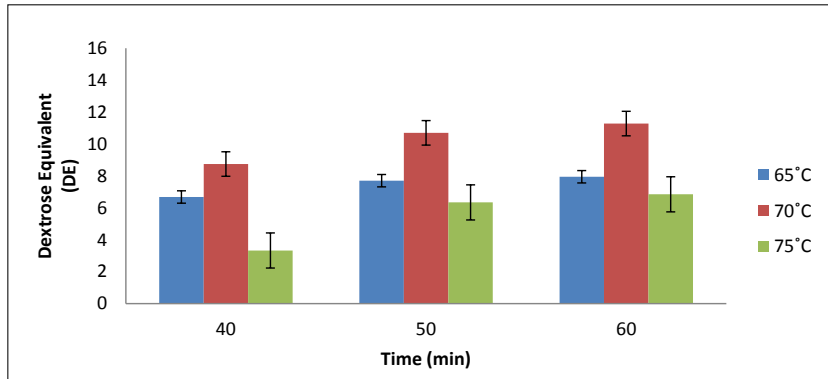

Figure 3a: Reducing sugar content during liquefaction of cassava at $\mathrm{pH} 6.5$

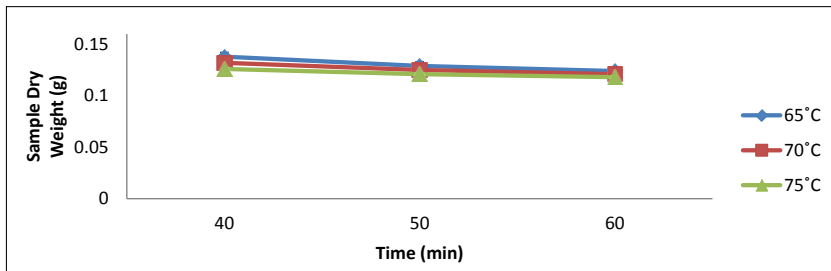

Figure 3b: Sample dry weight from liquefaction of cassava at $\mathrm{pH} 6.5$

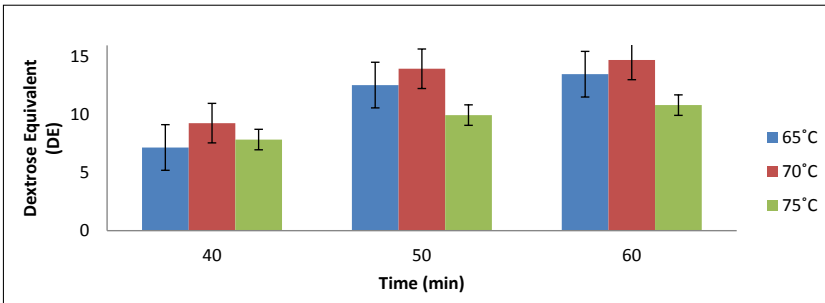

Figure 3c: Dextrose equivalent of syrup from liquefaction of cassava at $\mathrm{pH} 6.5$

were $12.25,17.48$ and $17.84 \%$; sample dry weight were $0.132,0.125$ and $0.121 \mathrm{~g}$, and dextrose equivalent were $9.28,13.98$ and $14.74 \mathrm{DE}$, respectively of 40,50 and $60 \mathrm{~min}$ of liquefaction time. Results however showed a significant increase in reducing sugar and dextrose equivalent but a significant decrease was observed in sample dry weight, respectively of liquefaction time. The results of the effect of $\mathrm{pH} 6.5$ on the liquefaction of cassava starch at $75^{\circ} \mathrm{C}$ showed that reducing sugars were 9.9, 12.07 and $12.79 \%$; sample dry weight were 0.126 , 0.121 and 0.118 ; and dextrose equivalent were 7.86 , 9.97 and $10.84 \mathrm{DE}$, respectively of 40,50 and $60 \mathrm{~min}$ of liquefaction time, a significant increase was observed in reducing sugar and dextrose equivalent, whereas there is significant decrease in sample dry weight in respect of liquefaction time. The effect of temperature on the kinetics showed that the highest level of reducing sugar and dextrose equivalent were recorded at $70^{\circ} \mathrm{C}$ which is higher than the value reported by Ayoola et al. (2013), who liquefied at $90^{\circ} \mathrm{C}$, which may have limited the hydrolytic strength of the $\alpha$-amylase, whose optimum temperature was $72^{\circ} \mathrm{C}$.

The results of the effect of $\mathrm{pH} 7$ on the kinetics of liquefaction and maltodextrin produced from cassava starch are shown in Figures 4a-c. At pH 7, liquefaction of cassava starch at $65^{\circ} \mathrm{C}$ showed that reducing sugars were $9.01,9.90$ and $9.91 \%$, respectively of 40,50 and $60 \mathrm{~min}$ of liquefaction time. Results showed an increase in respect of time, but there is no significant increase at 50 and $60 \mathrm{~min}$. The results showed that sample dry weight were $0.136,0.125$ and $0.121 \mathrm{~g}$, respectively of 40, 50 and 60 min of liquefaction time, results however showed significant decrease in respect of time. Dextrose equivalent were $6.62,7.92$ and $8.19 \mathrm{DE}$, respectively of 


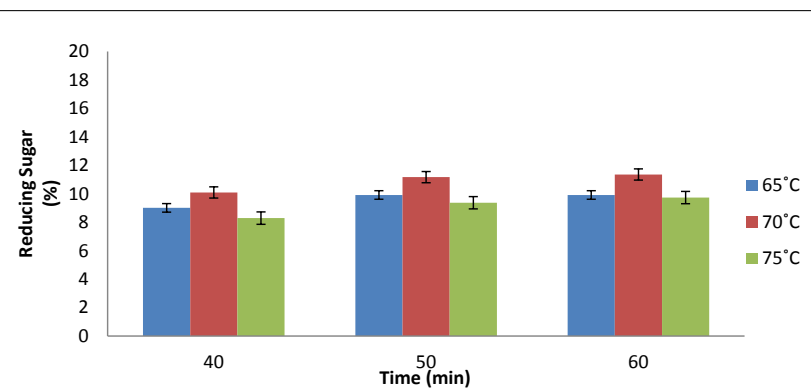

Figure 4a: Reducing sugar content during liquefaction of cassava at $\mathrm{pH} 7$

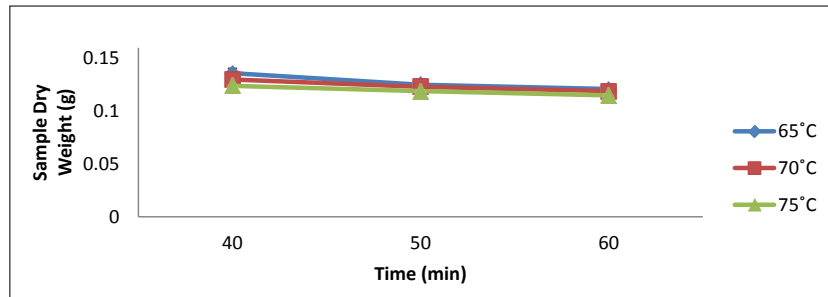

Figure 4b: Sample dry weight from liquefaction of cassava at $\mathrm{pH} 7$

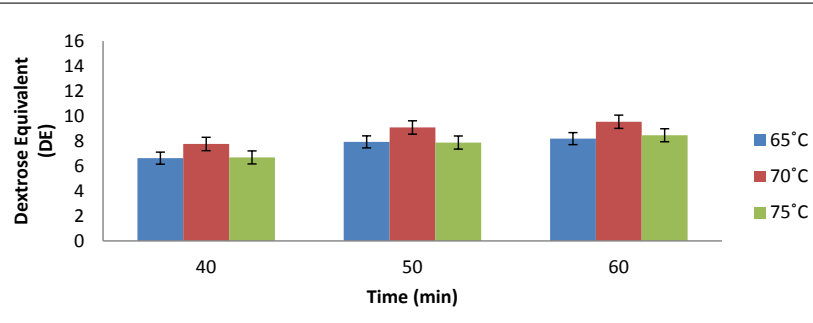

Figure 4c: Dextrose equivalent of syrup from liquefaction of cassava at $\mathrm{pH} 7$

40, 50 and 60 min of liquefaction time, results showed significant increase in respect of time.

The results of the effect of $\mathrm{pH} 7$ on the liquefaction of cassava starch at $70^{\circ} \mathrm{C}$ showed that reducing sugar were $10.09,11.17$ and $11.35 \%$, respectively of 40 , 50 and $60 \mathrm{~min}$ of liquefaction time, results showed a significant increase with respect of time. The results showed that sample dry weight were $0.13,0.123$ and $0.119 \mathrm{~g}$, respectively of 40,50 and $60 \mathrm{~min}$ of liquefaction time, results showed a significant decrease in respect of time. Dextrose equivalent were 7.76, 9.08 and 9.53 DE, respectively of 40,50 and 60 min of liquefaction time, results showed significant increase in respect of time.

The results of the effect of $\mathrm{pH} 7$ on the liquefaction of cassava starch at $75^{\circ} \mathrm{C}$ showed that reducing sugars were $8.28,9.36$ and $9.72 \%$, respectively of 40,50 and 60 min of liquefaction time, results showed significant increase with respect of time. The results showed that sample dry weight were $0.124,0.119$ and $0.115 \mathrm{~g}$, respectively of 40,50 and $60 \mathrm{~min}$ of liquefaction time, results also showed significant decrease in respect of time. Dextrose equivalent were $6.68,7.87$ and $8.46 \mathrm{DE}$, respectively of 40,50 and $60 \mathrm{~min}$ of liquefaction time, results however showed significant increase with respect of time.

The effect of temperature also showed that the highest level of reducing sugar and dextrose equivalent were observed at $70^{\circ} \mathrm{C}$. It was observed that samples dry weight decreased relatively as the temperature and $\mathrm{pH}$ increase. Results however showed that the optimum $\mathrm{pH}$, temperature and time of liquefaction of cassava starch hydrolysis were $6.5,70^{\circ} \mathrm{C}$ and $60 \mathrm{~min}$ respectively. The results were comparable with the previous report of Betiku and Ajala (2010).

\section{CONCLUSION}

The present study has demonstrated the effect of $\mathrm{pH}$ and temperature on the activities of alpha-amylase and maltodextrin produced from cassava. The results obtained in this research showed that the optimal reducing sugar and dextrose equivalent were $17.84 \%$ and $14.74 \mathrm{DE}$, respectively. However, the optimal $\mathrm{pH}$, temperature and time of liquefaction of cassava starch hydrolysis were $6.5,70^{\circ} \mathrm{C}$ and $60 \mathrm{~min}$, respectively. The maltodextrin obtained in this work may serve as a substrate to initiate a saccharification reaction in the production of glucose syrup.

\section{REFERENCES}

Aboje, P (2007). Production and Export of Glucose from cassava starch.

Aderibigbe AF, Anozie AN, Adejumo LA, Owolabi RU (2012).Optimization ofcassava starch hydrolysis by sorghum malt. New Clues in Sciences. 2: 50-58.

Adesanya OA, Oluyemi KA, Josiah SJ, Adesanya RA, Ofusori DA, et al. (2008). Ethanol production by Saccharomyces cerevisiae from cassava peels hydrolysate. Internet J. Microbiol. 5: 1-3.

Ayoola AA, Adeeyo AO, Efeovbokhan CV, Olasimbo DA (2013). Optimum hydrolysis conditions of cassava starch for glucose production. Int. J. Adv. Res. IT Engin. 2:1-4.

Bello-Perez IA, Sanchez-Hernandez L, Moreno-Damian E, Toro-vazquez J (2002). Laboratory scale production of maltodextrins and glucose syrup from banana starch. Acta. Cient. Venez. 53: 1-9.

Betiku E, Ajala O (2010). Enzymatic hydrolysis of breadfruit starch: Case study with utilization for gluconic acid production. Ife J. Tech.19: 10-14

Betiku E, Akindolani OO, Ismaila AR (2013). Enzymatic hydrolysis and optimizations of sweet potato (Ipomoea batatas) peel using a statistical approach. Braz. J. Chem. Eng. 30: 467-476. 
George AB (2004). Consumption of high-fructose corn syrup in beverages may play a role in the epidemic of obesity. Am. J. Clin. Nutr. 79: 537-543.

International Institute for Tropical Agriculture. (2004). Research highlights on Nigeria's cassava industry: Statistical handbook, Ibadan, Nigeria. pp. 43 -51.

JaneJL, ChenYY, Lee LF, McPherson AE, Wong KS, et al. (1999). Effects of amylopectin branch chain length and amylose content on the gelatinization and pasting properties of starch. Cereal Chem, 76: 629-637

Konsoula Z, Liakopoulou-Kyriakides M (2007). Co- production of alpha-amylase and beta-galactosidase by Bacillus subtilis in complex organic substrates. Bioresour. Technol. 98: 150-157.

Miller GL (1972). Use of dinitrosalicylic acid reagent for determination of reducing sugar. Anal. Chem. 31: 426-428.

Pandey A, Nigam P, Soccol CRVT, Soccol V, Singh D, Mohan R (2000). Advances in microbial amylases. Biotechnol. Appl. Biochem. 31: 135-152.

Ukwuru MU, Egbonu SE (2013) Recent development in cassava-based products research. Academic J. Food Resour. 1: 001-013. 